\title{
Youth engagement in high schools: Developing a multidimensional, critical approach to improving engagement for all students
}

\author{
Susan Yonezawa $\cdot$ Makeba Jones $\cdot$ Francine Joselowsky
}

Published online: 23 April 2009

(C) The Author(s) 2009. This article is published with open access at Springerlink.com

\begin{abstract}
What keeps students interested and engaged in school? Unfortunately, in today's climate of increased rigor in classrooms, we are simultaneously losing sight of the need to provide students with an education that is both challenging and stimulating. In this paper, we discuss youth disengagement and offer suggestions to improve our overall knowledge of academic engagement issues. We discuss the historical concept of engagement, more specifically, its shift from a uni-dimensional to multidimensional concept, and suggest that research concentrate on better understanding the interplay among setting and identity when examining issues of youth engagement in schools. Fundamentally, we strongly assert that engagement research needs to adopt a more critical stance that provides students with opportunities to examine and to critique the educational system in which they participate (or sometimes refuse to participate). Only when students see the purpose of engaging in schools, as students and agents of change, will engagement and students' academics and lives improve.
\end{abstract}

Keywords Engagement · Identity · Learning environments · Setting · Student/youth voice

\footnotetext{
The work for this article was generously supported by a grant from Carnegie Corporation of New York and Surdna Foundation. We also thank Jean Thomases, John Rogers, Alison Cook-Sather, \& Amanda Datnow for their helpful comments on earlier drafts.
}

S. Yonezawa $(\bowtie) \cdot$ M. Jones

Center for Research in Educational Equity, Assessment and Teaching Excellence (CREATE),

University of California, 9500 Gilman Drive, La Jolla, San Diego, CA 92093-0036, USA

e-mail: syonezawa@ucsd.edu

M. Jones

e-mail: m3jones@ucsd.edu

F. Joselowsky

Academy for Educational Development, Washington DC, USA

e-mail: francine@schoolandcommunity.org 
The history of education reform is a history of doing things to other people supposedly for their own good.

(Levin, 2000, p.1)

What helps students connect to learning in their classrooms and schools and what causes them to shut down and refuse to learn? For decades, educators, social scientists and researchers over the years have studied what aspects of schools and classrooms engage and disengage generations of youth (Achieve 2004, 2005; Blum and Libbey 2004; Tyack and Cuban 1995). The amount of energy devoted to studying engagement makes sense given that many believe engagement is critical to academic success. Students cannot simply go through the motions of school if they are to learn and retain information and be able to apply it critically in new contexts.

But over the past decade, the research community has struggled with adequately defining youth engagement. Early work on engagement overemphasized unidimensional definitions of the term focusing our attention on its behavior, cognitive, or emotional components. More recently, researchers have called for a multidimensional interpretation of engagement-one that acknowledges the behavioral, cognitive, and affective components of engagement simultaneously.

For the past 10 years, we have worked with young people in high schools in San Diego and around the country to encourage the development of youth engagement and voice in school reform. It has been our belief and experience that young people can be thoughtful contributors to changes needed in schools today. In this article, informed by our work and that of many others, we discuss how the concepts of youth disengagement and engagement have evolved over time-from uni-dimensional to multidimensional. We then argue that the current research on engagement must also incorporate a more critical dimension and discuss the role that the concepts of "setting," "identity," and "critical youth voice" should play in shaping the construct of engagement. Finally, informed by some of our own work with student co-researcher teams, we argue that future work on youth engagement should move away from the perspective that youth must appear engaged in a pre-ordained educational structure and culture and towards a vision that perceives youth as active and critical participants in the creation of those educational institutions.

\section{The disengagement of American youth in education}

America's school and community environments have failed to support adequately youth's academic and social-emotional development (McNeely and Falci 2004; McNeely et al. 2002; National Research Council and Institute of Medicine 2004). Students are dropping out of school at alarming rates and report feeling disconnected from the adults charged with educating and caring for them (Furrer and Skinner 2003). Kids do not know their teachers or feel that their teachers know and care about them; and many rarely see their counselors. Young people today often remain unconvinced that adults at schools are invested in their futures (Lee and Smith 1995, 1997; Tierney et al. 2005) and remain disconnected from adults despite the fact that supportive youth-adult relationships in schools are vital to students' education (Schultz and Cook-Sather 2001). 
For the past decade, we have worked with students across the country all of whom have been committed to examining the ways in which their schools and communities serve or fail to serve the needs of young people. We have run student inquiry groups (Jones and Yonezawa 2002), district-wide student focus groups (Yonezawa and Jones 2007) and student co-researcher projects (Jones and Yonezawa 2008a, b). These experiences have led us to conclude that students, when asked, are an excellent source of information and motivation. More than any other group in education, students are the ones who can quickly and accurately pinpoint the times and places that they are more or less engaged in their education-the mathematics classrooms where the teacher inspired them to connect mathematical formulas to life or the painfully boring science classroom where the teacher demonstrated lab materials but refused to let the students touch them.

Still, despite students' capabilities, the efforts of educators over the past decade to personalize American high schools has rarely engaged students directly. Reforms, such as reducing the size of high schools (e.g., the small schools movement) and improving student-teacher relationships (e.g., advisory programs), abound (Cotton 1996; Darling-Hammond et al. 2002a, b). Yet, despite reformers' efforts, the work remains disconnected from classrooms and kids' voices, often focusing on improving teacher culture and personalization, with less attention to curriculum and instruction, and the learning needs of young adolescents (Lee et al. 2000; Kahne et al. 2008). This is particularly troubling given that effective learning environments are critical to motivating young people to be active members of the classroom and achieve at high levels (Marks 2000; Newmann 1992; Newmann and Wehlage 1993; Nystrand and Gamaron 1991; Steinberg and Allen 2002).

We believe that addressing students as adolescents is important to meeting their overall needs-academic and psychosocial—nonetheless, educators and policymakers continue to be staunchly and solely focused on academics. The academic focus is welcome given past research that suggested some students were trapped in watered-down, remedial coursework that did little to improve their life chances (Anyon 1997; Gamaron 1992; Oakes et al. 1992). The dilemma, however, is that the field and the myriad of reforms over the last decade have simultaneously made few inroads to ensure that the quality of curriculum and pedagogical practices are pertinent to young people. Higher behavioral engagement increases students' expectations of success (Bandura 1997; Eccles and Barber 1999). But American high schools retain a traditional core curriculum that addresses classic content through traditional pedagogical practices (Stigler and Hiebert 1999).

Some of the pressure for schools to increase academic success-without attending to curriculum and pedagogical advancements and how students perceive these advancements per se-results from the frenzy of accountability that has focused educators' attention since the arrival of No Child Left Behind (NCLB) in 2001. NCLB, the federal accountability act that requires all schools, districts, and states to test their students across reading and mathematics in grades 3-8 and once in high school, has forced schools to show "annual yearly progress" (AYP) via students' standardized test scores, otherwise risk de-funding or restructuring. Schools, particularly those serving traditionally low-performing student populations, find 
they have few resources to spend on improving pedagogical practices that may or may not result in improved test scores.

Thus, despite well-intentioned efforts by all, the disconnect-between the academic focus driven home in today's schools and youth's needs and interestshas created a crisis, particularly in our nation's high schools (Lee and Smith 1995, 1997). Adolescents are increasingly at odds with their schooling experiences that emphasize a one-size-fits-all model. Reversing this historic trend means expanding the focus of school reform from solely improving academic achievement to improving the general engagement of young people in their schooling, in the classroom, and in their overall development (Newmann 1992; Pittman et al. 2003; Rose 2004). To this end, we ask: What do youth need to improve their engagement in school?

\section{School engagement: The current state of the concept, measures and outcomes}

Part of the difficulty with remedying this disconnect between the current state of schooling in America and the needs of youth is our collectively poor understanding of engagement as a theoretical construct. Over the past decade, researchers have examined engagement from a number of orientations that operationalize engagement as "participation," "motivation," "attachment," "self-regulated behavior," "anti-alienating behavior," "thoughtfulness," "belonging," and "investment" in school related content, ideas and skills (Fredericks et al. 2004).

In the following section, we describe the past decade of work in engagement and make the argument that the literature on engagement has been a mix of studies that examined individual dimensions of the term. These studies which focused largely on behavioral conceptions of engagement were helpful in laying out a connection between engagement and achievement. But they are limited in how well they capture all the facets of engagement and, as a consequence, researchers are now calling for a more multidimensional definition of engagement in research.

\section{Unidimensional constructs of engagement}

Early work on student engagement tended to characterize it in uni-dimensional terms. Fredericks et al. (2004) provide a helpful delineation of early engagement research as studying the term from one of three dimensions: behavioral, cognitive, and emotional. More specifically, Fredericks et al. (2004) argue that much of the research literature over the past decade or more treated engagement as a static concept with these three separate and distinct components and erroneously assumed that studying one component would help the field understand student engagement as a whole. Such a static view of engagement suggested a linear relationship between educational programs or interventions and improving students' engagement.

For example, much of the earlier research on youth engagement studied the concept's behavioral components. Behaviorally minded researchers examined how students acted, typically defining engagement as positive actions or conduct, perseverance, and participation in school-related activities such as attention to a 
particular school task, membership in athletics, or avoidance of unruly behaviors (Birch and Ladd 1998; Finn and Voelkl 1993). Although much of this research began in the 1990s, behaviorally-oriented research is still conducted today, including a recent study of Latin American immigrant students by Green et al. (2008) that used a measurement tool called the "Academic Engagement Scale" and asked students to rate themselves on three behaviors that are considered necessary for school success: finishing work, turning homework in on time, and paying close attention in class.

In addition, engagement researchers have also often used psychological engagement measures to study the cognitive aspects of engagement. Cognitive engagement referred to students' psychological and social investment in their learning and mastering ideas, knowledge and skills (Newmann 1992). For example, Newmann and Wehlage (1993) asserted that there are three overarching criteria to define what they term "authentic achievement" which in many respects paralleled the concept of cognitive engagement. To be truly engaged, they claimed students had to (1) "construct meaning and produce knowledge," (2) "use disciplined inquiry to construct meaning," and (3) "aim their work toward production of discourse, products, and performances that have value or meaning beyond success in school" (p. 1). Work on cognitive engagement also often focused on increasing students' intrinsic motivation to learn (Ames 1992; Brophy 1987) and/or self-regulated metacognitive strategies (e.g., summarizing) to improve learning (Zimmerman 1990).

The final area of early engagement research focused on emotional engagement. This type of engagement referred to the role of students' affect in schools and classrooms, "including interest, boredom, happiness, sadness, and anxiety" (Fredericks et al. 2004, p. 63). Researchers such as Finn (1989) and Voelkl (1997, 1995) claimed emotional engagement also included the extent to which students felt connected to school and had a sense of belonging or membership. Program developers working to enhance the social-emotional needs of youth claimed that these programs increased engagement and correlated positively with achievement (Klem and Connell 2004). For example, Blum and Libbey (2004) argued that increased school connectedness correlated to educational motivation, classroom engagement and better attendance, which were linked to higher academic achievement. Unfortunately, few of these studies appeared in peer-reviewed publications, thereby exacerbating the problem of weak evidence that emotional engagement by youth in schools resulted in higher academic achievement (Glanville and Wildhagen 2007).

To summarize, the past decade has provided a wealth of research on engagement. But much of the early engagement research incorporated definitions of engagement from one of three categories: behavioral, cognitive, and emotional (Fredericks et al. 2004).

Behavioral engagement studies measured how students act as an observational measure of how engrossed they are in a school task (Birch and Ladd 1998; Finn and Voelkl, 1993; Green et al. 2008).

Cognitive engagement studies examined students' investment in learning and mastering ideas, knowledge and skills (Newmann 1992; Newmann and Wehlage 
1993 ) and students' intrinsic motivation to learn (Ames 1992; Brophy 1987) and/ or use of self-regulated metacognitive strategies (e.g., summarizing) (Zimmerman 1990).

Emotional engagement studies referred to students' affect in schools "including interest, boredom, happiness, sadness, and anxiety" (Finn 1989; Fredericks et al. 2004, p. 63; Voelkl 1995, 1997).

\section{Multidimensional constructs of engagement}

What has been the shift in engagement related research over the past 10 years? The shift has occurred mostly in the move away from uni-dimensional definitions of engagement - as behavior, cognitive or emotional-and more multidimensional notions of engagement that combine two or more of these aspects of engagement under study. While this "shift" has yet to be completed, more recent research is working hard to combine several aspects of engagement in their studies, compared to earlier work which did not.

For example, newer studies adopt a more multidimensional approach to engagement by analyzing connections between more than one type-emotional and behavioral engagement. Given that behavioral engagement has shown a tighter relationship with achievement, researchers are attempting to prove that other types of engagement such as emotional or cognitive can improve achievement by first improving behavioral engagement. For instance, Green and her colleagues (2008) showed that students' perceptions of emotional engagement through supportive adult relationships at their school were correlated with their level of behavioral engagement in school.

In addition to the appeal of linking engagement to student achievement, why else are researchers approaching engagement through a more multidimensional lens? There is increasing agreement that representing engagement as a static concept with separate and distinct components (cognition, emotion, and behavior) neglects the critical relationships among youth, their identities, and the contexts in which they live and learn. That is, while behavioral engagement has shown the tightest relationship between its measures such as time-on-task and student achievement, academic measures linked to cognitive and emotional engagement have shown less success. Research suggesting a positive connection between "softer" forms of engagement, and academic achievement is emerging, but, as of yet, rarely available in peer-reviewed publications (Blum and Libbey 2004; Glanville and Wildhagen 2007; Green et al. 2008; Klem and Connell 2004).

A more multidimensional conception of engagement may also help remedy the methodological difficulties still apparent within the engagement research literature. For example, the designs of most engagement studies rely on teacher ratings and student self-report data through surveys or student focus groups to measure student perceptions, reactions, and even metacognitive thinking about their social and academic experiences in school settings (Fredericks et al. 2004). The variety in operational definitions of engagement and how these definitions are measured has resulted in a jumble of assessment packages and scales that all purport to measure 
engagement. Multidimensional definitions of engagement may help consolidate the hodgepodge of engagement approaches and provide greater explanatory power. Glanville and Wildhagen (2007) recently conducted confirmatory factor analysis (CFA) on previous research on engagement that used NELS:88 to test whether the indicators used were acceptable measures of the types of engagement they claimed to measure. They found that only the early model by Finn and Voelkl (1993) which embraced a more multidimensional concept of school engagement was adequate.

A multidimensional approach to engagement may help push the field into producing empirical data that moves beyond correlational relationships and supports the claim that improving students' engagement increases students' academic achievement. For too long, studies in one area of engagement (e.g., behavioral) made claims about another area (cognitive) without empirically addressing what distinguishes the two and how each component impacts student learning and achievement. As Fredericks and colleagues write, "because there has been considerable research on how students behave, feel, and think, the attempt to conceptualize and examine portions of the literature under the label 'engagement' [has been] potentially problematic; it [has resulted] in a proliferation of constructs, definitions, and measures of concepts that differ slightly, thereby doing little to improve conceptual clarity" (2004, p. 60).

A move to a more multidimensional approach to engagement is occurring and shows great promise to further the field conceptually and empirically. Yet, despite the potential of this multidimensional approach, the concept of engagement as it relates to school settings needs to be pushed further if it is to provide the evidence and clarity needed to improve student learning and achievement.

\section{The importance of setting, identity and critical youth voice}

So what are the next steps? How can we add to the research literature on engagement in ways that help educators, reformers, and policymakers create educational opportunities and institutions that engage young people's minds and hearts in ways that inspire them to actively participate in their learning and education?

Like those current working on a more complicated version of engagement, we, too, call for a more multi-dimensional and critical characterization of the concept of engagement. However, we push the conversation even further by claiming that we must pay particular attention to three additional components - setting, identity and critical youth voice - as we study youth engagement.

Examining the features of youth settings to support and sustain engagement

The first key component to a deeper understanding of engagement requires a renewed look at the role that setting plays in youth engagement. Reformers have embraced the idea that altering educational settings will help improve student achievement but have not always made the connection to engagement. But understanding the facets and interplay of social settings involving youth and adults 
are central to improving engagement. Youth do not live, work and play in black boxes. Their homes, schools, neighborhoods, clubs, teams, and workplaces help determine how engaged they do or do not become.

In our work with student co-research teams, we have found that creating thoughtful educational settings for our students is essential to engaging them in the work. The settings we try to create pay attention to creating positive adult-youth relationships and peer relationships among youth by deliberately allowing youth to create respectful rules, norms and tasks for each other to collaborate on and complete. The settings our teams work within often embody a school or classroom space, sometimes after school and sometimes during school, but because of the attention we pay to the setting creation, the students often do not equate their work in the student co-research teams as schoolwork since it tends to feel so different-it is more often a place where students are expected to hold each other accountable for tasks they have decided are meaningful and engaging.

Unfortunately, much of the past research on social settings has been completed by community psychologists who have focused on the impact of settings on individuals rather than on the social settings or systems that surround individuals (Tseng and Seidman 2007). It is our belief that the contexts that surround individuals are important in shaping how adults and youth interact and consequently the ways in which these interactions affect the students' academic futures.

We are slowing building greater understanding of the importance of setting on engagement. For example, researchers are actively studying the ways in which afterschool programs (Mahoney et al. 2005), teacher expectations (Cohen et al. 2003), youth-adult relationships (Gambone et al. 2002), peer social networks (Ream and Rumberger 2008) and the allocation of resources (Oakes 2003; Tseng and Seidman 2007), among other features, affect social settings and how youth and adults interact within them. The belief of setting researchers and theorists is that a better understanding of what makes particular settings more effective and supportive for youth will enable policymakers and educators to alter social settings systematically to improve setting outcomes.

Yet, even as we gain ground on social setting theory, today's educational settings are often much more complicated than they appeared even a few years ago. We know from talking to students in schools today they are learning in an everchanging, high tech world that defies traditional notions of space and time. For instance, Alvermann and Eakle (2007) write about how youth today are engrossed in a world that is "increasingly blurred by information communication technologies that tend to heed neither place nor space boundaries." Students tell us that texting, blogging, instant messaging and emailing are forms of communication that challenge our now old-fashioned binary notions of in- and out-of-school time. Studying adolescences attending after-school programs in public libraries and museums, Alvermann and Eakle also revealed how what they call the "deregulated attention economy" reshapes how student do, re-do and undo schooling.

While we build understanding about how the processes and practices through which today's various educational settings support or undermine engagement and learning, unanswered questions remain. We must know more about the interplay between engagement that is planned (e.g., scripted curriculum/lesson study) versus 
unplanned (teachable moments) settings. We must unpack how the processes of learning and engagement vary when the tasks at-hand require cognitive interdependence of many people (group work) versus individuals (Hutchins 1990, 1991). We must study how power dynamics shape relationships and interactions among actors in school and classroom settings (Fine et al. 2004), and how cultural and economic power as a "feature" of settings support and derail educational change (Wells and Serna 1996).

We believe a fruitful area of social setting research might build from prior research showing how students are capable of performing complex cognitive tasks outside of school that they appear incapable of in classrooms (Lave and Wenger 1991). This has certainly been our experience with students in the student coresearch teams we work with in San Diego (Jones and Yonezawa 2008a, b). This research and our work suggest that how participants become part of a community of practice, and develop an identity within and to that community, shapes their ability to participate fully in the community (Wenger 1998). This helps explain why when students study diverse subjects such as math, geography, or language arts, those tasks studied in real-world contexts of athletics, local neighborhoods, automotive repair, or shopping are often more manageable, understandable and engaging. Some of the research on after-school and non-traditional schooling activities speaks to these findings as well (Nasir and Hand 2008; Rose 2004).

We suspect that new settings may afford students the chance to "reinvent" themselves. The students in our research teams often find that teachers and administrators begin to see the students differently-less as a troublemaker and more as a serious student-after participating in the research team work. Similarly, recent research by Hopkins (2008) found this to be the case among students in workrelated learning (WRL) settings in the United Kingdom. When questioned in focus groups, students reported that that key to help them access the benefits of the WRL programs was the fact that the activities occurred outside of traditional school settings. Students reported that having the opportunity to attend WRL courses tapped into their interests, but it was the opportunity to attend WRL activities on college campuses with their superior physical amenities, older student body and smaller teaching groups that held the students' attention. The new WRL setting differed so dramatically from students' traditional school environments-and the peer pressures and other disruptive behaviors common on secondary campusesthat students adamantly argued that the WRL courses could never be held on the secondary campuses and have the same effect. Hopkins's research strongly suggests that the interplay between setting and identity is critical to understanding engagement.

Studying the relationships between youth identity and settings

This then brings us to our next point-a second key feature of future research on engagement should consider issues of youth identity. Our work with students in secondary school research teams has shown us that students see themselves very differently than adults see them. They fancy themselves to be the "rebel" the "smart one," the "gang banger," or the "friendly girl," and these self-proclaimed 
identities - some of which have racial and cultural tones-can shape how they interact with one another and adults.

Yet, despite the intense role identity plays in kids' lives, the role of identity in influencing engagement remains understudied. Much of the work thus far has focused less on identity per se and more on students' background characteristics as a proxy for identity. For instance, to increase engagement among historically disenfranchised student populations, school systems have tried to alter settings to meet students' specific multicultural or linguistic needs (Finn and Rock 1997; Finn and Voelkl 1993). Multicultural education, bilingual education, and single-gender schooling are specific, deliberate attempts to alter the curricular offerings and structures of schooling to mesh with students' cultural, linguistic, and gendered background characteristics.

It is true that some researchers and educators, particularly those who study lowincome, students of color, have long advocated incorporating students' background knowledge into the classroom by suggesting that educators draw from the "funds of knowledge" that all students carry with them into school each and every day (Moll and Gonzalez 2004). But encouraging educators to incorporate students' backgrounds in the curriculum and instruction to increase engagement failed in many cases to increase engagement because educators were ill equipped to "take up" the knowledge students brought into classrooms (Thomson and Hall 2008).

Yet youth backgrounds and youth identity are not equivalent concepts. While one's gender, race and language (although less so) remain fairly static over time, identity changes and develops (sometimes rapidly) over time across various contexts and as individuals engage with different communities. Because of this fluid nature of identity building and its important interactions with social settings, we believe that any study of social settings and engagement requires a simultaneous concern with identity formation. Interestingly, one area of research that has explored the connection between identity formation and learning environments can be found in science education research. Science educators and researchers have long been concerned with the disenfranchisement of students and teachers who feel disconnected from scientific curricula. As such many informal educational contexts have emerged that coax youth and educators into "doing science" by reframing who participates, where science occurs, and in doing so, the identities of the participants (Rahm and Ash 2008).

In the student co-research teams we helped establish, the students rarely saw themselves as researchers before they began the work. Their prior experience with research was primarily in science class, mixing chemicals or writing up a lab experiment. Occasionally a student reported that he or she had filled out a survey for school as a research subject. However, during and after participating in the student co-research teams, the students we worked with often began to see themselves differently. They found they could speak with confidence about designing research, protecting subject confidentiality, and forming conclusions based on the research they had designed and conducted, and the data they had analyzed. We began to realize, as did the students, that their identity had shifted from borderline high school student to promising researcher. 
While our work with the student co-research teams was an in-school, decidedly academic activity other researchers have shown that non-academic activities can also be studied for their academic impact. A recent study by Nasir and Hand (2008) of African American high school basketball players on the court and in mathematics classrooms is a good example of work that is trying to understand how nonacademic engaging settings for youth outside of school can inform in-school engagement, particularly for underserved populations. In their work studying basketball players, Nasir and Hand claim that engaging in hands-on activities helped alter students' identities as they moved through the different settings of basketball court and math classroom because identity is formed partly through practice. Using a term they call "practice-linked identities," the researchers showed that students' identities are shaped and re-shaped are they engage in a given practice (e.g., basketball or mathematics). The more a person is allowed to really engage in the practice's domain (play basketball or do mathematics) the more likely they are to participate intensely and thus have their identity altered. What is especially interesting is that Nasir and Hand found in their study that the youth were more likely to be given "access to the domain" in basketball (allowed to really play all aspects of the game) compared to their experience in mathematics class where they were more often observers (p. 174). It is not surprising then that students were therefore more likely to develop a basketball identity than a mathematics identity. For Nasir and Hand "engagement then has to do with students' feelings of competence and mastery in a social context, as well as their sense that the context will offer relationships that support and value their unique selves" (p. 145).

Emerging research on social settings, identity, and engagement suggest to us that altering social settings can impact the ways in which individuals in those settings interact with one another. Changing the ways schools and classrooms are organized and resources allocated can reshape what Tseng and Seidman (2007) refer to as transactional social processes between individuals. Altering how youth and educators interact can, in the end, have a broad impact on the engagement within various settings and, ultimately, students' academic outcomes.

Engaging youth in the critical study of education

But the issue closest to our hearts has been the raising of critical youth voice in support of student engagement. For the past 10 years, we have advocated for students to play a more active and important role in the shaping of their educations. Our fundamental premise has been that adolescents have important knowledge about schooling from a students' perspective and that this knowledge-of which adults are not privy - can help people with power make important changes and improvements to schools and classrooms (Jones and Yonezawa 2002, 2008a, b; Joselowsky 2005).

But this perspective, that students are agents of change, remains a challenge as adults still see students as youth to be developed, supervised or controlled. We believe that for youth engagement to flourish, students must be given opportunities to do more than participate in academically rigorous, adult-sanctioned activities. Rather youth must partake in the active and critical creation of the educational 
institutions they attend. The student co-research teams we help create at high schools are an example of the ways in which adults can help create opportunities for students to formulate a critical youth voice in schools and communities (Jones and Yonezawa 2008a, b; Yonezawa and Jones in press).

Unfortunately, opportunities for youth to speak up and be heard are not commonplace. Systemic educational change requires involvement from multiple constituencies and stakeholders in the school-community; however, youth have rarely been considered as "partners" in education reform (Loutzenheiser 2002; Nieto 1994; Silva and Rubin 2003). In fact, in the 500 pages of the No Child Left Behind (NCLB) legislation, the notion that students can help improve their schools does not appear once. Moreover, youth who struggle academically or socially have been most often ignored (or silenced) when adults come together to advance new ideas aimed at improving school environments (Fine 1991; Forum for Youth Investment 2005; Rubin and Silva 2003; Schultz and Cook-Sather 2001; Weiss 2003). This continues to be the case in most education contexts, despite researchers' efforts to document marginalized youths' school experiences (Cook-Sather 2002; Mitra 2001; Thiessen and Cook-Sather 2007; Yonezawa and Jones 2007).

Recently, researchers and community activists have called for increasing the civic, moral, and critical engagement of youth in shaping their educational opportunities. Proponents of youth voice and engagement, and we agree, argue that, to be meaningful to young people, education needs to embrace a more critical dimension (Cook-Sather 2006; Fielding, 2001a, 2004a, b; Fine et al. 2007; Joselowsky 2005) that encourages students to make meaning, articulate interests, set agendas, and enact power as an end in itself (Rogers et al. 2007). Tseng and Seidman (2007) recognize the power differential between teachers and students as "one of the central differences between youth organizing programs and other youth settings such as classrooms and youth development programs". The key difference here is the idea that youth organizers ${ }^{1}$ - those that advocate for youth voicebelieve that students should not be encouraged just to navigate school-they should help challenge and change it as well (Cook-Sather 2007a).

The student voice movement-ourselves included-has long considered the importance of setting and identity in its work. Rudduck et al. (1996), proponents of critical youth voice, have argued for over a decade that students' critical engagement at schools must be developed with full acknowledgement and recognition of their lives inside and outside of school including the ways that they perceive opportunities or injustices. That is because how students see themselves - their identities - are developed in part through their interactions with social settings including schools. It is often in school where students "learn" that they are "smart" or "slow" and it is the interaction between their developing identities and their school and non-school settings that further shape their identities and the settings themselves (Johnston and Nicholls 1995). Fielding (2001b) has also written extensively about the ways that organizational structures and cultures as

\footnotetext{
1 While we use the term youth organizers here rather loosely, we recognize that many researchers and activists who advocate for youth voice-ourselves included-do not use this term to describe themselves.
} 
well as social and cultural hierarchies shape student voice efforts including who is allowed to speak, to whom, about what, in what language, and, importantly, who listens.

Critical youth voice advocates argue that pursuing the development of youth voice across a variety of settings is important because it can help reshape the identities of the youth and the settings in which they are immersed. Engaging youth in re-shaping their educational opportunities benefit the youths' identities (Rudduck 2007) as they are afforded access to new knowledge, skills, and relationships that empower them and simultaneously ready them for post-secondary work. For example, Oakes, Rogers and their colleagues $(2002,2006)$ created a series of what they called "social design experiments" known locally as the "Futures Project" which included creating new communities of practice with a group of Los Angeles area high school students. In these newly enacted communities, the diverse group of students studied, designed, and completed sociological research projects on issues that mattered deeply to them and their communities. In doing so, they became sociological apprentices and participated in social inquiry in their school, communities, and that the nearby university. These activities fundamentally changed the way the Futures students saw themselves. Rogers et al. (2007) claim that the students were able to take on new and more powerful identities-that embodied skills and knowledge and ways of being that would help the youth in the future schooling, and as they pursued college-level work.

Critical youth engagement can also provide considerable value to educational institutions (Cook-Sather 2007b; Lodge 2005). Students are uniquely situated as "insiders" in school contexts with ready access to information about what does and does not work-information to which adults are often not privy (Levin 2000). With training from willing adults, student co-researchers can work individually or in teams to study issues of educational importance in their schools and communities (Fielding 2001a; Jones and Yonezawa 2008a, b; Yonezawa and Jones 2007). Youth can also be engaged in dialogue with adults on governance boards, committees, and even in their classrooms to shape district, school and classroom level policies.

The notion of engaging students in educational change is not new. It has early roots in the "student power" movement of the 1960s and early 1970s (Levin 2000; Rudduck, 2007). The student voice movement's recent resurgence however argues that greater civic engagement by students in school and community change efforts can help students develop into participatory and justice-oriented citizens (Westheimer and Kahne 2004) and see the value in becoming well educated (Feldman et al. 2007; Rubin and Giarelli 2006; Syvertsen et al. 2007). In addition, developing moral engagement in youth is seen as a way to emphasize "questions of justice, ethical conduct, and reactions to interpersonal circumstances" (Thorkildsen 2007a, p. 115; Thorkildsen 2007b).

\section{A word of caution}

We, like most other youth voice proponents, recognize that encouraging youth to take a critical perspective of their educational experiences is not without its 
challenges. More than once we have found ourselves having to mediate between well intended adults and youth trying to being heard. Moreover, we have also found ourselves trying to help youth communicate better with one another when they fail to see eye to eye with each other. Youth, like adults, do not embody a singular culture or political perspective, and divisions between adults and youth and within groups of young people can foster struggles over the nature of their collective work and who gets to define it (Fielding 2001b; Silva 2001). For instance, in a study we conducted with one youth group, the students in the inquiry groups hotly debated notions of tracking practices with some advocating for greater tracking while others were disturbed by what they saw as the inherent inequities in a stratified school system (Jones and Yonezawa 2002). Similarly, Bragg (2001) discusses how difficult it can be for adults to listen to and take seriously youth opinions that adults disagree with, or even find distasteful.

Another common danger in promoting youth critical engagement is adult domination (intended or unintended) and the creation of false opportunities (Mitra 2004, 2007; Silva 2001). Lodge (2005) describes how efforts to promote a critical youth engagement can range from those that promote active student participation to those that encourage relatively passive involvement by youth. She further explains that some critical engagement projects are more about improving organizations and less about developing the people within those organizations-the youth included. Projects established to be more dialogic in nature are, Lodge explains, the most likely to product democratic and critical engagement of youth.

\section{Conclusion}

Youth engagement in school has been studied for decades and has been compartmentalized as having distinct parts such as behavioral, cognitive and emotional. Unfortunately, this divide and conquer approach to youth engagement has resulted in a less than satisfactory understanding about how youth become engaged (or disengaged) in their education and how to remedy this disconnection.

Currently, the field is undergoing a shift to a more multidimensional view of engagement. This shift brings together more than one of the prior dimensionsbehavioral, cognitive or emotional-and tries to combine them into studies of multiple dimensions of engagement. Although this is a step forward in the concept's development, we believe that this shift is insufficient to enriching to concept of engagement. Consequently, in this article, we call for a more complex rendition of youth engagement that brings together prior research on the various dimensions of engagement as well as research on social settings, identity, and critical youth voice.

Our attention to the areas of setting, identity and critical youth voice come from our years of experience in creating spaces for youth in schools to become part of the effort to improve their educational institutions. We have found, through our work with secondary students in inquiry groups, focus groups, and student co-research teams that much of the work on student engagement thus far has typically advocated for finding ways for students to learn to "do school." The end goal of much research on student engagement has been for students to be successfully incorporated into the 
structures and cultures of educational institutions. Researchers and practitioners hope that students will become more attentive, productive, and, although rarely stated, compliant. Little work on youth engagement seeks to disrupt schooling as it is currently enacted or to engage students in critically assessing their educational opportunities-or lack thereof.

Yet, student engagement cannot simply be about teaching kids to "do school." Our goals must be loftier and our reach longer. Rather we must ask ourselves in what ways and with what tools can we re-engage students in learning. A first step towards this will be our own efforts to re-orient the settings in which our children live and work-schools, classrooms, and community centers-in ways that help re-shape and support their unique identities and their potentially powerful voices. Only when we improve how we create more engaging settings for youth can we alter youth identity and voice, and, ultimately, improve students' academic achievement. A multidimensional and critical view of engagement-that considers the interplay among setting, identity, and critical youth voice-can go a long way in improving youth engagement in school.

Open Access This article is distributed under the terms of the Creative Commons Attribution Noncommercial License which permits any noncommercial use, distribution, and reproduction in any medium, provided the original author(s) and source are credited.

\section{References}

Achieve Inc. (2004). The expectations gap: A 50-state review of high school graduation requirements. Washington, DC: American Diploma Project.

Achieve Inc. (2005). Rising to the challenge: Are high school graduates prepared for college and work? Washington, DC: American Diploma Project.

Alvermann, D., \& Eakle, A. J. (2007). Dissolving learning boundaries: The doing, re-doing, and undoing of school. In A. Cook-Sather \& D. Thiessen (Eds.), International handbook of student experience in elementary and secondary school (pp. 143-166). The Netherlands: Springer.

Ames, C. (1992). Goals, structure, and student motivation. Journal of Educational Psychology, 84(3), 261-271.

Anyon, J. (1997). Ghetto schooling. New York: Teachers College Press.

Bandura, A. (1997). Self-efficacy: The exercise of control. New York: Freeman.

Birch, S. H., \& Ladd, G. W. (1998). Children's interpersonal behaviors and the teacher-child relationship. Developmental Psychology, 34(5), 934-946.

Blum, R. W., \& Libbey, H. P. (Eds.). (2004). School connectedness: Strengthening health and education outcomes for teenagers. Special issue, Journal of School Health, 74(7), 229-299.

Bragg, S. (2001). Taking a joke: Learning from the voices we don't want to hear. Forum, 43(2), 70-73.

Brophy, J. (1987). Teacher effects research and teacher quality. Journal of Classroom Interaction, 22(1), 14-23.

Cohen, D. K., Raudenbush, S. W., \& Ball, D. L. (2003). Resources, instruction and research. Educational Evaluation and Policy Analysis, 25, 119-142.

Cook-Sather, A. (2002). Authorizing students' perspectives: Toward trust, dialogue, and change in education. Educational Researcher, 31(4), 3-14.

Cook-Sather, A. (2006). Education is translation: A metaphor for change in learning and teaching. Philadelphia: University of Pennsylvania Press.

Cook-Sather, A. (2007a). Translating researchers: Re-imagining the work of investigating students' experiences in school. In A. Cook-Sather \& D. Thiessen (Eds.), International handbook of student experience in elementary and secondary school (pp. 829-872). The Netherlands: Springer. 
Cook-Sather, A. (2007b). What would happen if we treated students as those with opinions that matter? The benefits to principals and teachers of supporting youth engagement in school. NASSP Bulletin, 91(4), 342-362.

Cotton, K. (1996). School size, school climate, and student performance (Northwest Regional Educational Laboratory School Improvement Research Series Close-Up \#20). Retrieved September 19, 2001 from http://www.nwrel.org/scpd/sirs/10/c020.html.

Darling-Hammond, L., Alexander, M., \& Prince, D. (2002a). Redesigning schools: What matters and what works: 10 features of good small schools. Palo Alto, CA: Stanford Redesign Network.

Darling-Hammond, L., Ancess, J., \& Ort, S. (2002b). Reinventing high school: Outcomes of the coalition campus schools project. American Educational Research Journal, 39(3), 639-673.

Eccles, J., \& Barber, B. (1999). Student council, volunteering, basketball, or marching band: What kind of extracurricular involvement matters? Journal of Adolescent Research, 14(1), 10-43.

Feldman, L., Pasek, J., Romer, D., \& Hall-Jamieson, K. (2007). Identifying best practices in civic education: Lessons from the student voices program. American Journal of Education, 114(1), 75-100.

Fielding, M. (2001a). Students as radical agents of change. Journal of Educational Change, 2, $123-141$.

Fielding, M. (2001b). Beyond the rhetoric of student voice: New departures or constraints in the transformation of 21st century schooling. Forum, 43(2), 100-110.

Fielding, M. (2004a). 'New wave' student voice and the renewal of civic society. London Review of Education, 2(3), 197-217.

Fielding, M. (2004b). Transformative approaches to student voice: Theoretical underpinnings, recalcitrant realities. British Educational Research Journal, 30(2), 295-311.

Fine, M. (1991). Framing dropouts: Notes on the politics of an urban public high school. New York: SUNY.

Fine, M., Roberts, R., Torre, E., \& Bloom, J. (2004). Echoes of brown: Youth documenting and performing the legacy of Brown v. Board of Education. New York: Teachers College Press.

Fine, M., Torre, M. E., Burns, A., \& Payne, Y. (2007). Youth research/participatory methods for reform. In A. Cook-Sather \& D. Thiessen (Eds.), International handbook of student experience in elementary and secondary school (pp. 805-828). The Netherlands: Springer.

Finn, J. D. (1989). Withdrawing from school. Review of Educational Research, 59, 117-142.

Finn, J. D., \& Rock, D. A. (1997). Academic success among students at risk for school failure. Journal of Applied Psychology, 82, 221-234.

Finn, J. D., \& Voelkl, K. E. (1993). School characteristics related to student engagement. Journal of Negro Education, 62, 249-268.

Forum for Youth Investment. (2005). Youth engagement in education change: Working definitions and lessons from the field. Washington, DC: Forum for Youth Investment and Impact Strategies.

Fredericks, J. A., Blumenfeld, P., \& Paris, A. H. (2004). School engagement: Potential of the concept, state of the evidence. Review of Educational Research, 74(1), 59-109.

Furrer, C., \& Skinner, E. (2003). Sense of relatedness as a factor in children's academic engagement and performance. Journal of Educational Psychology, 95, 148-162.

Gamaron, A. (1992). Access to excellence: Assignment to honors English classes in the transition from middle to high school. Educational Evaluation and Policy Analysis, 14(3), 185-204.

Gambone, M. A., Klem, A. M., \& Connell, J. P. (2002). Finding out what matters for youth: Testing key links in a community action framework for youth development. Philadelphia, PA: Philadelphia Youth Development Strategies, Inc., and Institute for Research and Reform in Education.

Glanville, J. L., \& Wildhagen, T. (2007). The measurement of school engagement: Assessing dimensionality and measurement invariance across race and ethnicity. Educational and Psychological Measurement, 67, 1019-1041.

Green, G., Rhodes, J., Hirsch, A. H., Suarez-Orozco, C., \& Camic, P. M. (2008). Supportive adult relationships and the academic engagement of Latin American immigrant youth. Journal of School Psychology, 46, 393-412.

Hopkins, E. A. (2008). Work-related learning: Hearing students' voices. Educational Action Research, 16, 209-219.

Hutchins, E. (1990). The technology of team navigation. In J. Galegher, R. E. Kraut, \& C. Egibo (Eds.), Intellectual teamwork (pp. 191-220). Hillsdale, NJ: Lawrence Erlbaum.

Hutchins, E. (1991). Organizing work by adaptation. Organizational Science, 2(1), 14-38.

Johnston, P. H., \& Nicholls, J. G. (1995). Voices we want to hear and voices we don't. Theory into Practice, 34(2), 94-100. 
Jones, M., \& Yonezawa, S. (2002). Student voice, cultural change: Using inquiry in school reform. Equity and Excellence in Education, 35(3), 245-254.

Jones, M., \& Yonezawa, S. (2008a). Inviting students to analyze their learning experience. In M. Pollock (Ed.), Everyday antiracism: Concrete ways to successfully navigate the relevance of race in school (pp. 212-216). New York: The New Press.

Jones, M., \& Yonezawa, S. (2008b). Student driven-research: When students gather and analyze data about their school, everyone learns something. Educational Leadership, 66(4), 65-69.

Joselowsky, F. (2005). Students as co-constructors of the learning experience and environment: Youth engagement and high school reform, High School Redesign, VUE (Voices in Urban Education) Number 8, Summer 2005, Annenberg Institute for School Reform., Providence, R.I. http://www. annenberginstitute.org/VUE/summer05/Joselowsky.html.

Kahne, J. E., Sporte, S. E., de la Torre, M., \& Easton, J. Q. (2008). Small high schools on a larger scale: The impact of school conversions in Chicago. Educational Evaluation and Policy Analysis, 309(3), 281-315.

Klem, A., \& Connell, J. (2004). Relationships matter: Linking teacher support to student engagement and achievement. Philadelphia: Institute for Research and Reform in Education.

Lave, J., \& Wenger, E. (1991). Situated learning and legitimate peripheral participation. Cambridge English: Cambridge University Press.

Lee, V., Smerdon, B. A., Alfeld-Liro, C., \& Brown, S. L. (2000). Inside large and small high schools: Curriculum and social relations. Educational Evaluation and Policy Analysis, 22(2), 147-171.

Lee, V., \& Smith, J. (1995). The effects of high school restructuring and size on gains in achievement and engagement for early secondary school students. Sociology of Education, 68(4), 271-290.

Lee, V., \& Smith, J. (1997). High school size: Which works best and for whom? Educational Evaluation and Policy Analysis, 19(3), 205-227.

Levin, B. (2000). Putting students at the centre of education reform. Journal of Educational Change, 1(2), $155-172$.

Lodge, C. (2005). From hearing voices to engaging in dialogue: Problematising student participation in school improvement. Journal of Educational Change, 6, 125-146.

Loutzenheiser, L. W. (2002). Being seen and heard: Listening to young women in alternative schools. Anthropology and Education Quarterly, 33(4), 441-464.

Mahoney, J. L., Larson, R. W., \& Eccles, J. S. (Eds.). (2005). Organized activities as contexts of development: Extracurricular activities, after-school and community programs. Mahwah, NJ: Lawrence Erlbaum.

Marks, H. M. (2000). Student engagement in instructional activity: Patterns in elementary, middle and high school years. American Educational Research Journal, 37, 153-184.

McNeely, C., \& Falci, C. (2004). School connectedness and the transition into and out of health-risk behavior among adolescents: A comparison of social belonging and teacher support. Journal of School Health, 74(7), 284-292.

McNeely, C., Nonnemaker, J. M., \& Blum, R. W. (2002). Promoting school connectedness: Evidence from the National Longitudinal Study of Adolescent Health. Journal of School Health, 72(4), $138-146$.

Mitra, D. (2001). Opening the floodgates: Giving students a voice in school reform. Forum, 43(2), 91-94.

Mitra, D. (2004). The significance of students: Can increasing "student voice" in schools lead to gains in youth development? Teachers College Record, 106(4), 651-688.

Mitra, D. (2007). Student voice in school reform: From listening to leadership. In A. Cook-Sather \& D. Thiessen (Eds.), International handbook of student experience in elementary and secondary school (pp. 727-744). The Netherlands: Springer.

Moll, L., \& Gonzalez, N. (2004). Engaging life: A funds of knowledge approach to multicultural education. In J. Banks \& C. McGee Banks (Eds.), Handbook of research on multicultural education (2nd ed., pp. 699-715). New York: Jossey-Bass.

Nasir, N. S., \& Hand, V. (2008). From the court to the classroom: Opportunities for engagement, learning, and identity in basketball and classroom mathematics. Journal of the Learning Sciences, 17, 143-179.

National Research Council and the Institute of Medicine. (2004). Engaging schools: Fostering high school students' motivation to learn. Committee on Increasing High School Student's Engagement and Motivation to Learn. Board on Children, Youth and Families, Division of Behavioral and Social Sciences and Education. Washington, DC: The National Academies Press.

Newmann, F. M. (Ed.). (1992). Student engagement and achievement in American secondary schools. New York: Teachers College Press. 
Newmann, F. M., \& Wehlage, G. (1993). Five standards of authentic instruction. Educational Leadership, $50(7), 8-12$.

Nieto, S. (1994). Lessons from students on creating a chance to dream. Harvard Educational Review, 64(4), 392-426.

Nystrand, M., \& Gamaron, A. (1991). Instructional discourse, student engagement, and literature achievement. Research in the Teaching of English, 25(3), 261-290.

Oakes, J. (2003). Critical conditions for excellence and equity. UCLA: UC ACCORD.

Oakes, J., Gamoran, A., \& Page, R. (1992). Curriculum differentiation: Opportunities, outcomes, and meanings. In P. Jackson (Ed.), Handbook of research on curriculum (pp. 570-608). New York: Macmillan.

Oakes, J., Rogers, J., Lipton, M., \& Morrell, E. (2002). The social construction of college access. In W. G. Tierney \& L. S. Hagedorn (Eds.), Increasing access to college: Extending possibilities for all students (pp. 105-122). New York: SUNY.

Oakes, J., Rogers, J., \& with Lipton, M. (2006). Learning power: Organizing for education and justice. New York: Teachers College Press.

Pittman, K., Irby, M., Tolman, J., Yohalem, N., \& Ferber, T. (2003). Preventing problems, promoting development, encouraging engagement: Competing priorities or inseparable goals? Washington, D.C.: Forum for Youth Investment.

Rahm, J., \& Ash, D. (2008). Learning environments at the margin: Case studies of disenfrancished youth doing science at an aquarium and an after-school program. Learning Environments Research, 11(1), 49-62.

Ream, R. K., \& Rumberger, R. W. (2008). Student engagement, peer social capital, and school dropout among Mexican American and non-Latino white students. Sociology of Education, 81, 109-139.

Rogers, J., Morrell, E., \& Enyedy, N. (2007). Studying the struggle: Contexts for learning and identity development for urban youth. American Behavioral Scientist, 51(3), 419-443.

Rose, M. (2004). The mind at work. New York: Viking.

Rubin, B. C., \& Giarelli, J. M. (2006). Civic education for diverse citizens in global times: Rethinking theory and practice. New Jersey: Lawrence Erlbaum Associates.

Rubin, B. C., \& Silva, E. M. (2003). Critical voices in school reform: Students living through change. New York: RoutledgeFalmer.

Rudduck, J. (2007). Student voice, engagement and school reform. In A. Cook-Sather \& D. Thiessen (Eds.), International handbook of student experience in elementary and secondary school (pp. 587610). The Netherlands: Springer.

Rudduck, J., Chaplain, R., \& Wallace, G. (Eds.). (1996). School improvement: What can pupils tell us? London: David Fulton.

Schultz, J., \& Cook-Sather, A. (Eds.). (2001). In our own words: Students' perspectives on school. Lanham, MD: Rowman \& Littlefield Publishers Inc.

Silva, E. (2001). Squeaky wheels and flat tires: A case study of students as reform participants. Forum, 43(2), 95-99.

Silva, E., \& Rubin, B. (2003). Missing voices: Listening to students' experiences with school reform. In B. Rubin \& E. Silva (Eds.), Critical voices in school reform: Students living through change (pp. 1-7). London: RoutledgeFalmer.

Steinberg, A., \& Allen, L. (2002). From large to small: Strategies for personalizing the high school. Boston: Jobs for the Future.

Stigler, J. W., \& Hiebert, J. (1999). The teaching gap: Best ideas from the world's teachers for improving education in the classroom. New York: The Free Press.

Syvertsen, A. K., Flanagan, C. A., \& Stout, M. D. (2007). Best practices in civic education: Changes in students' civic outcomes. Center for Information and Research on Civic Learning and Engagement (CIRCLE) Working Paper, 57.

Thiessen, D., \& Cook-Sather, A. (Eds.). (2007). International handbook of student experience in elementary and secondary school. The Netherlands: Springer.

Thomson, P., \& Hall, C. (2008). Opportunities missed and/or thwarted? "Funds of knowledge" meet the English national curriculum. Curriculum Journal, 19(2), 87-103.

Thorkildsen, T. (2007a). Adolescents' moral engagement in urban settings. Theory Into Practice, 46(2), $113-120$.

Thorkildsen, T. (2007b). The role of personal standards in second graders' moral and academic engagement. In A. Cook-Sather \& D. Thiessen (Eds.), International handbook of student experience in elementary and secondary school (pp. 193-231). The Netherlands: Springer. 
Tierney, W. G., Corwin, Z. B., \& Colyar, J. E. (Eds.). (2005). Preparing for college: Nine elements of effective outreach. Albany, NY: SUNY Press.

Tseng, V., \& Seidman, E. (2007). A systems framework for understanding social settings. American Journal of Community Psychology, 39, 217-228.

Tyack, D., \& Cuban, L. (1995). Tinkering toward utopia: A century of public school reform. Cambridge, MA: Harvard University Press.

Voelkl, K. (1995). School warmth, student participation, and achievement. Journal of Experimental Education, 63(2), 127-138.

Voelkl, K. (1997). Identification with school. American Journal of Education, 105(3), 294-318.

Weiss, M. (2003). Youth rising, Oakland, CA: Applied Research Center. The applied Research Center. Retrieved December 8, 2008 from http://www.arc.org.

Wells, A. S., \& Serna, I. (1996). The politics of culture: Understanding local political resistance to detracking in racially mixed schools. Harvard Educational Review, 66(1), 93-118.

Wenger, E. (1998). Communities of practice: Learning, meaning and identity. Cambridge, England: Cambridge University Press.

Westheimer, J., \& Kahne, J. (2004). What kind of citizen? The politics of educating for democracy. American Educational Research Journal, 41(2), 237-269.

Yonezawa, S., \& Jones, M. (2007). Using students' experiences in the classroom to evaluate and inform secondary school reform. In A. Cook-Sather \& D. Thiessen (Eds.), International handbook of student experience in elementary and secondary school (pp. 681-710). The Netherlands: Springer.

Yonezawa, S., \& Jones, M. (in press). Reforming schools from the inside out: Student voice and the potential influence on school policies and practices. Theory into Practice.

Zimmerman, B. J. (1990). Self-regulated learning and academic achievement: An overview. Educational Psychologist, 21, 3-17. 